\title{
Electrochemical Deposition of Ni-Co/SiC Nanocomposite Coatings for Marine Environment
}

\author{
Baosong $\mathrm{Li}^{1, *}$, Weiwei Zhang ${ }^{2}$ \\ College of Mechanics and Materials, Hohai University, Nanjing 211100, China \\ ${ }^{2}$ College of Mechanical and Electrical Engineering, Hohai University, Changzhou 213022, China \\ *E-mail: bsli@hhu.edu.cn
}

doi: $10.20964 / 2017.08 .19$

Received: 28 April 2017 / Accepted: 25 May 2017 / Published: 12 July 2017

\begin{abstract}
$\mathrm{Ni}-\mathrm{Co} / \mathrm{SiC}$ nanocomposite coatings were prepared by electrodeposition from a modified watt type Ni$\mathrm{Co}$ bath containing suspended $\mathrm{SiC}$ nanoparticles. The effects of $\mathrm{SiC}$ nanoparticles on the structure and morphology of Ni-Co coatings were studied by scanning electron microscopy (SEM), energy spectrum analysis (EDS), X-ray diffraction (XRD) and electrochemical technique. The electrochemical corrosion properties of $\mathrm{Ni}-\mathrm{Co} / \mathrm{SiC}$ composite coatings were studied by EIS and Tafel methods. The results show that the addition of $\mathrm{Co}^{2+}$ ions in the bath improves the refinement phase, reduces the porosity and strengthens the corrosion resistance of the nanocomposite deposits. SiC and Co content in the deposits varied with the change of deposition parameters and $\mathrm{SiC}$ nanoparticles concentration in the bath. The SiC nanoparticles have the dual role of promoting the nucleation and enhancing the hardness of the Ni-Co alloys which improved the wear resistance of the $\mathrm{Ni}-\mathrm{Co} / \mathrm{SiC}$ coatings. The incorporation of $\mathrm{SiC}$ nanoparticles into $\mathrm{Ni}-\mathrm{Co}$ alloy matrix alters the chemical composition, increases the microhardness, significantly enhances the anti-corrosion behavior and wear resistance of the composite coatings. The composite coatings can provide long-term protection for metal parts in marine environment and have a good application prospect in the field of marine protection.
\end{abstract}

Keywords: $\mathrm{Ni}-\mathrm{Co} / \mathrm{SiC}$ nanocomposite coatings; Electrodeposition; wear resistance; corrosion behavior; marine protection

\section{$\underline{\text { FULL TEXT }}$}

(C) 2017 The Authors. Published by ESG (www.electrochemsci.org). This article is an open access article distributed under the terms and conditions of the Creative Commons Attribution license (http://creativecommons.org/licenses/by/4.0/). 